\title{
Presença do miniconto na literatura brasileira
}

\author{
Marcelo Spalding ${ }^{l}$
}

\begin{abstract}
This study analyzed the presence of short-short stories in contemporary Brazilian literature and the historical roots of this genre. As no studies have been conducted in Brazil about it so far, we examined the modern prose of Machado de Assis and Oswald de Andrade as originators of it in Brazil and came to the name of Dalton Trevisan as a central player in its dissemination, starting in the 1960s. Later reinvented in the 1990s, some of it achieved the status of single-phrase narratives. Already in the $21 \mathrm{st}$ Century, several authors launched collections of short-short stories, such as Fernando Bonasi, Luiz Arraes, Carlos Herculano Lopes, or organized them, as Laís Chaffe and Marcelino Freire.
\end{abstract}

Keywords: short-short stories; micro-fiction; Dalton Trevisan; Brazilian literature

Resumo: Este artigo procura demonstrar a presença do miniconto na literatura brasileira contemporânea e suas raízes históricas. Diante da quase absoluta ausência de estudos sobre o tema no Brasil, tentamos buscar na prosa moderna de Machado de Assis e Oswald de Andrade alguns precursores, chegando ao nome de Dalton Trevisan como central para a difusão do gênero no país a partir dos anos sessenta e para a reinvenção do miniconto nos anos noventa, quando este chegou a ser transformado numa narrativa unifrásica. Já no século XXI, apresentamos diversos autores que lançaram livros de miniconto no Brasil, como Fernando Bonasi, Luiz Arraes, Carlos Herculano Lopes, ou os organizaram, como Laís Chaffe e Marcelino Freire. Palavras-chave: miniconto, minificção, Dalton Trevisan, literatura brasileira

\section{Introdução}

Pelo menos desde Edgar Allan Poe, com seu "Filosofia da Composição", tem se estudado o conto como um gênero próprio, com estética e estrutura distintas, por exemplo, do romance. Entretanto, das noções fundacionais às ponderações contemporâneas muito se tem escrito sobre o conto, reforçando ou refutando seu caráter de gênero, sem que se chegue a conceitos cristalizados. 
Faccioli, por exemplo, depois de percorrer as teorias do conto de Edgar Allan Poe, Anton Tchekhov, Julio Cortázar, Ernest Hemingway e Ricardo Piglia, chegará a três leis do gênero: a intensidade, o adensamento narrativo e o efeito que deve causar em seu leitor. Para a estudiosa e também contista, Piglia consegue ser a síntese de seus predecessores ao formular a idéia de que o conto narra simultaneamente uma história aparente e uma história oculta: "conta-se uma história enquanto se está contando outra, e a maneira como as duas se articulam encerra os problemas técnicos do gênero" (2000: 57). A própria autora, porém, chama a atenção para o fato de que também as demais modalidades literárias partilham dessas características.

Dessa forma, se há dificuldades em definirmos o miniconto isso se deve não (apenas) ao prefixo "mini-", e sim às diversas e produtivas discussões sobre o gênero conto. E ainda mais difícil do que definir o miniconto é precisar quando ele teria surgido.

Lagmanovich, professor argentino da Universidade de Tucumán e autor de um dos primeiros livros teóricos sobre o tema, em antologia sobre o miniconto hispânico, La outra mirada, de 2005, lembra que poucos assim o chamavam quando apareceram as primeiras ficções que extrapolavam os limites do gênero conto, como as de José Arreola ou Jorge Luis Borges. Daqueles anos iniciais pode-se dizer que se conhecia o objeto mas não se tinha uma conceituação e sistematização, além do que havia freqüente confusão entre este tipo de texto e os poemas em prosa ou aforismos. O estudioso deixa claro que quando se refere a microrrelato está se referindo a um gênero literário produzido nos séculos $\mathrm{XX}$ e XXI: "as narrativas breves sempre existiram nas composições dos sumérios, nos escritos bíblicos, na narrativa oral africana, (...) mas ao fazer um corte temporal pensamos no desenvolvimento de um gênero literário com leis próprias” (2005: 10).

Investigando os precursores que levam ao miniconto da metade do século XX, Lagmanovich lembra de poetas modernos como Rubén Darío e da forte influência que franceses como Charles Baudelaire tiveram nesta geração, citando o singular volume $\mathrm{Pe}$ quenos poemas em prosa ${ }^{2}$ como obra importante para a condensação narrativa.

Neste artigo, nosso objetivo é investigar a presença do miniconto na literatura brasileira, buscando identificar seus predecessores e alcançando um breve panorama da produção contemporânea.

\section{Precursores do miniconto no Brasil}

A história do miniconto no Brasil deve começar por uma negativa: "uma tradição brasileira de mini-relatos, não devemos esperar" (ERIK, 2004: 153). Esta negativa se faz sentir na quase total ausência de estudos acadêmicos sobre o tema e no fato de a primeira antologia específica, como as existentes nos Estados Unidos e na América Latina, ter surgido apenas em 2004.

Essa carência de estudos não significa que a miniaturização do conto ocorrida ao longo do tempo nos Estados Unidos e na América Latina não tenha também se dado no Brasil. Já no começo dos anos setenta, quatro mini-contos de Dalton Trevisan foram publicados na famosa antologia organizada por Alfredo Bosi O conto brasileiro contemporâneo, o que evidencia a presença destes textos no país, ainda que na época não se diferenciasse eles do "conto em si". Tais contos evidenciam que a valorização da concisão e da velocidade como valores poéticos são anteriores a esta metade do século XX e remetem, ainda, pelo

2 Chamado também de Spleen de Paris, ambos títulos atribuídos à coleção de textos depois da morte do autor que não havia, portanto, batizado seus escritos de "poemas em prosa". 
menos aos modernos e modernistas, onde encontraremos inclusive narrativas unifrásicas muito semelhantes ao célebre "O dinossauro", de Augusto Monterroso.

Em raro artigo sobre o miniconto brasileiro, o professor Karl Erik lembra que "dificilmente encontramos mini-relatos entre os clássicos modernos como Machado de Assis e Lima Barreto, ainda que a rica tradição de crônicas que eles inauguram contém traços estilísticos que posteriormente aparecem nas mini-ficções contemporâneas" (2004: 153). Há um conto de Machado, entretanto, que freqüentemente é apontado como um dos precursores do gênero no Brasil, "Um Apólogo".

O conto, publicado em Várias Histórias, de 1986, narra com apenas 650 palavras a fábula de uma agulha e uma linha que travam interessante diálogo sobre a importância maior de uma ou de outra, finalizando com a constatação de um "professor de melancolia" que também ele tem servido de agulha a muita linha ordinária. Se por um lado "Um Apólogo" é uma exceção na contística machadiana, cuja extensão costuma ter em torno de dez páginas, não se pode negar que a concisão seja valor fundamental para o Bruxo do Cosme Velho.

Já no primeiro romance de sua chamada segunda fase, Machado deixa emergir para a própria narrativa sua preocupação com a concisão. Brás Cubas contava que voltara ao Rio porque sua mãe estava à morte quanto interrompe a narrativa com estas palavras: "Vim... Mas não; não alonguemos este capítulo. Às vezes, esqueço-me a escrever, e a pena vai comendo papel, com grave prejuízo meu, que sou autor. Capítulos compridos quadram melhor a leitores pesadões" (ASSIS, 1997: 68).

Assim não surpreende que em Memórias Póstumas de Brás Cubas se encontre tantos capítulos de um parágrafo ou uma página, como "Uma reflexão imoral" (XVI), "Virgília" (XXII), "A pêndula" (LVI), "O senão do livro" (LXXI), "O jantar" (XCIII), "Flores de Antanho" (XCV), "De repouso" (CII), "Epitáfio" (CXXV), "Na câmara" (CXXVIII), o unifrásico "Inutilidade" (CXXVI), os seqüentes "Não vou" (CXLIII), "Utilidade relativa" (CXLIV) e "Simples repetição" (CXLV) e o derradeiro e célebre "Das negativas" (CLX). Um deles, "Notas" (XLV), pela narratividade, totalidade e potência narrativa, bem poderia ter sido escrito como miniconto para uma destas antologias contemporâneas de mínis:

soluços, lágrimas, casa armada, veludo preto nos portais, um homem que veio vestir o cadáver, outro que tomou a medida do caixão, caixão, essa, tocheiros, convites, convidados que entravam, lentamente, a passo surdo, e apertavam a mão à família, alguns tristes, todos sérios e calados, padre e sacristão, rezas, aspersões d'água benta, o fechar do caixão a prego e martelo, seis pessoas que o tomam da essa, e o levantam, e o descem a custo pela escada, não obstante os gritos, soluços e novas lágrimas da família, e vão até o coche fúnebre, e o colocam em cima e traspassam e apertam as correias, o rodar do coche, o rodar dos carros, um a um... Isto que parece um simples inventário eram notas que eu havia tomado para um capítulo triste e vulgar que não escrevo. (ASSIS, 1997: 96).

Mas, parodiando o Mestre, não alonguemos nós esse artigo. Falar da velocidade dos modernos é lembrar sobretudo de Oswald de Andrade.

Os estudiosos têm sido unânimes em apontar a influência do futurismo italiano na obra de Oswald desde que ele conhecera em Paris as idéias de Marinetti, idéias que celebram a modernidade, a comunicação, a guerra e, sobretudo, a velocidade. Para os futuristas, a arte precisa acompanhar o novo século que traz consigo novos sistemas de comunicação, informação e transporte, devendo abrir-se para a multiplicidade, a simultaneidade, a velocidade e a síntese, repudiando o velho e o conhecido. 
É a partir da transposição do cerne modernizante do movimento para a realidade brasileira que Oswald criará os romances, artigos e manifestos que o tornaram protagonista do Modernismo brasileiro, sendo o célebre "Manifesto Pau-Brasil" caso exemplar dessa transposição. Nele o autor já fala especificamente em agilidade, "Ágil a poesia" (ANDRADE, 1972: 267), e em síntese: "O trabalho contra o detalhe naturalista - pela síntese; contra a morbidez romântica - pelo equilíbrio geômetra e pelo acabamento técnico; contra a cópia, pela invenção e pela surpresa" (ANDRADE, 1972: 268).

Agilidade e síntese também são a tônica de Memórias Sentimentais de João Miramar, "primeira grande experiência de prosa modernista na ficção brasileira, procurando romper as barreiras com a poesia e narrando num estilo alusivo e elíptico" (CÂNDIDO e CASTELLO, 1997: 89). Escrito no mesmo ano do Manifesto Pau-Brasil, o romance intensifica a divisão de capítulos e o estilo elíptico que já vimos no Memórias de Machado, trabalhando a realidade "com apelo à sugestão, à alusão, à metáfora e ao trocadilho (...) cuja unificação é feita no espírito do leitor, dispensando a rigorosa concatenação lógica" (CÂNDIDO e CASTELLO, 1997: 28).

Em meio a este romance de estilo telegráfico, encontramos inclusive um capítulo extremamente interessante para este estudo, um capítulo unifrásico que muito bem poderia ser considerado o menor conto do século $\mathrm{XX}$ ou a mais antiga minificção do século $\mathrm{XX}$, ainda que não tenha sido escrito com esta intenção.

\section{Natal}

Minha sogra ficou avó. (ANDRADE, 1991: 70)

Em quatro palavras, dezoito letras, Oswald dá à luz uma personagem ao mesmo tempo que demonstra todo o descaso, ou mesmo desconfiança, do narrador-protagonista por aquela que ao final seria sua provedora financeira, a filha. Campos acredita que este capítulo unifrásico compreende, por abreviatura crítica, toda uma narratologia de idealização familiar burguesa: "fórmula de happy-end, aqui desnudada, (...) este capítulo-frase oswaldiano pontua as vicissitudes das relações naturais perturbadas pelas derrapagens extraconjugais e pelas oscilações de pecúnia (1983p. 184-5)”. É a expansão da narrativa para além do dito.

Até aqui demonstramos como a concisão e a velocidade permeiam a literatura moderna brasileira a partir de dois dos seus maiores representantes e como alguns capítulos de seus romances fragmentados poderiam ser classificados, em outro contexto, de miniconto. Mas neste ponto é preciso avançar do romance, onde os demais capítulos ajudam na construção do enredo e na significação das micronarrativas que pinçamos do todo - mas que não são isoladas -, para o conto. Antes, porém, é preciso deixar desde já claro que escolhemos transitar pelo caminho da prosa, mais especificamente do conto em direção ao miniconto, ou ao conto extremamente breve, em detrimento do caminho da poesia em direção ao mesmo lugar.

É por este motivo que não citamos nesta breve e incompleta genealogia do miniconto brasileiro, por exemplo, poemas narrativos de Manuel Bandeira, como o "Poema do beco", de 1936. Karl Erik (2004), aliás, salta da sua negativa sobre a existência de mini-relatos nos clássicos modernos brasileiros diretamente para o último livro de Guimarães Rosa, Tutaméia, lançado em 1967, pulando também, desta forma, o romance oswaldiano destacado neste estudo.

Tutaméia, ou Terceiras Estórias, contém quarenta contos de mais ou menos três a cinco páginas, publicados quase todos em revistas. O título, que significa "quase nada" 
ou "ninharia", talvez indicasse para alguns leitores que se tratasse de um livro menos importante na obra canonizada pelo romance épico Grande Sertão: Veredas e pelas novelas extensas de Sagarana e Corpo de Baile. Mas, segundo Erik, um "olhar mais atento logo descobre que se trata de uma obra prima, principalmente, pela invenção de uma poética da prosa curta, da Estória como Guimarães Rosa a denominaria" (2004: 153-154). A partir daí, Erik fará uma análise dos quatro prefácios que o livro esconde e aproximará a concepção de fragmento para Rosa com a concepção do fragmento romântico para adiante identificar relação semelhante entre essa contística de Rosa e as crônicas de Clarice Lispector, "para quem a crônica serve de matéria prima a ser depurada e enriquecida" (2004: 155). E termina sua breve investigação sobre as origens do miniconto brasileiro em Dalton Trevisan, que, num processo inverso ao de Rosa e Clarice, "depura seu processo de condensação e subtração, retrabalhando obsessivamente o material de livros anteriores cada vez mais enxutos e depurado para criar unidades mínimas" (2004: 157).

\section{Dalton Trevisan e a reinvenção do miniconto}

Dalton Trevisan está presente nos diversos momentos em que o miniconto brasileiro aparece na superfície canônica da crítica. Além da presença na antologia de Bosi acima referida, Trevisan é um dos dois brasileiros, ao lado de Rubem Fonseca, a figurar na antologia em espanhol Ficción mínima: muestra del cuento breve en América, organizada por Jiménez Emán em 1996.

Autor de pequenos folhetos com feitio de cordel que enviava para amigos e conhecidos, sem arriscar a publicação em volume - folhetos estes fora de circulação comercial e hoje desconsiderados pelo autor -, Trevisan estréia de fato na literatura em 1959 com Novelas Nada Exemplares, estréia hoje considerada uma "renovação estilística e temática num momento literário saturado pela mesmice" (SANCHES NETO, 1996: 13). De fato estamos em um momento anterior à rica produção contística dos anos sessenta, tida como uma década onde "dezenas de escritores foram revelados ou solidificaram suas carreiras literárias através deste gênero específico" (HOHLFELDT, 1988: 12). Moriconi concorda que nos anos sessenta tenha ocorrido uma explosão de qualidade no campo da ficção curta brasileira, lembrando que "são desta década algumas das realizações máximas no gênero em nosso país. (...) Os contos dos anos 60 falam de nossa contemporaneidade, quase sempre urbana, agitada por conflitos psicológicos e sociais" (2001: 193).

Cândido encontra nas mudanças sociais da época a explicação para esse crescimento da narrativa curta. $O$ crítico lembra que não se trata da coexistência dos gêneros conto e romance, mas do desdobramento e da justaposição deles, resultando daí textos indefiníveis como romances que parecem reportagens, contos semelhantes a poemas ou crônicas, narrativas que são cenas de teatro, textos feitos com a justaposição de recortes. Enfim, "a ficção recebe na carne mais sensível o impacto do boom jornalístico moderno, do espantoso incremento de revistas e pequenos seminários, da propaganda, da televisão, das vanguardas poéticas que atuam desde o fim dos anos 50" (1987: 209). A ambição criadora agora desloca-se das grandes obras (Cândido cita os grandes projetos de antanho como os romances em vários volumes Clico da cana-de-açúcar ou O tempo e o vento) para o pequeno fazer de cada texto: "O ímpeto narrativo se atomiza e a unidade ideal acaba sendo o conto, a crônica, o sketch, que permitem manter a tensão difícil da violência, do insólito ou da visão fulgurante" (1987: 213-4). Tais observações são muito caras para um estudo sobre o miniconto, que, como veremos, começa a aparecer nos livros de Trevisan exatamente nos anos sessenta e causam grande confusão quanto ao gênero. 
Novelas Nada Exemplares, apesar de não ser sua primeira obra, surpreendeu a crítica com sua concisão extrema, concisão esta que se reflete até mesmo na construção das frases. Estudiosos notaram "que entre as primeiras versões conhecidas [a dos cordéis] e aquelas reunidas em volumes, seus contos modificavam-se sempre, reduzindo-se, concentrando-se" (HOHLFELDT, 1988: 161).

O título de "novelas" para um livro de contos, parodie ou não Cervantes e seu Novelas ejemplares, prenuncia como Trevisan trabalhará ao longo de toda carreira literária no limite das definições de gênero, sem preocupar-se com elas, permanecendo fiel a sua temática e a partir daí intensificando sua estética hoje identificada como minimalista. $\mathrm{O}$ autor se coloca "fora da concepção tradicional do conto, criando uma forma de expressão pessoal que põe em xeque os parâmetros da crítica” (SANCHES NETO, 1996: 126).

Já na obra de estréia aparecem contos com menos de duas páginas, como "Idílio" e "Meu avô", mas são contos curtos de Cemitério de Elefantes, publicado em 1964, como "Uma vela para Dario" e o conto que dá título ao livro, que tornaram-se célebres e presenças constantes de antologias de contos.

"Uma vela para Dario", que hoje chamamos de miniconto, tem pouco mais de 500 palavras, mas era à época sem muito esforço identificado como "conto em si". Mais do que narrar a cena de um homem passando mal, Trevisan cria um clima de enorme tensão ao opor o homem agonizante aos transeuntes despreocupados e chamar a atenção para o sumiço gradual dos objetos de Dario, culminando com a perda da própria aliança. Da chegada apressada do protagonista à chuva que encerra a narrativa, todos os elementos convergem essencialmente para o drama numa intensidade perturbadora e desconcertante.

Já “À Margem do Rio", conto mais curto de Trevisan até então, com pouco mais de uma página, narra a história de um assassinato com início, meio e fim, apresentando as personagens, o conflito e o desfecho trágico da vítima, que cobrava certa dívida do pai de família e assassino Abílio. Novamente temos todos os elementos do conto, tensão, intensidade, efeito, narratividade, tudo em espaço extremamente exíguo.

Ainda nos anos sessenta, Trevisan publicaria outros quatro livros de contos (Morte na Praça, O Vampiro de Curitiba, A Guerra Conjugal e Desastres do Amor), sempre colocando em cena suas já conhecidas personagens e tendo como cenário a provinciana Curitiba, num processo de bricolagem funcional que alterna elementos estruturais para contar a mesma história, permitindo assim a compactação das narrativas de uma forma, se não inovadora, pelo menos perturbadora.

O reconhecimento do autor pela crítica é rápido: já no começo dos anos setenta, Trevisan é incluído na famosa antologia $O$ conto brasileiro contemporâneo, organizada por Alfredo Bosi, ao lado de Guimarães Rosa, Lygia Fagundes Telles, Osman Lins, Clarice Lispector, Rubem Fonseca e outros treze autores. Bosi, na apresentação, chama a atenção para o fato de que nos contos de Trevisan a concisão é uma obsessão do essencial que parece beirar a crônica, "mas dela se afasta pelo tom pungente ou grotesco que preside à sucessão das frases, e faz de cada detalhe um índice do extremo desamparo e da extrema crueldade que rege os destinos do homem sem nome na cidade moderna" (1995: 17).

Curiosamente, Trevisan é quem tem mais contos publicados na antologia, cinco, contra uma média de dois ou três dos demais autores. Destes cinco contos, quatro têm menos de duas páginas - "Cemitério de Elefantes", de 1964, "Bonde", "O ciclista" e "Apelo", de 1968 - e um tem pouco mais de duas páginas - "Eis a primavera”, de 1972 -, o que indica que a brevidade dos textos de Trevisan já era um diferencial na metade do século, ainda que o termo miniconto não seja atribuído à sua obra pela crítica da época. 
Mas se nos primeiros livros Trevisan já chama a atenção pela estética de feitio minimalista, é com $A h, e ́$ ?, de 1994, que o autor leva o miniconto a uma espécie de limite, limite esse que já vinha sendo esboçado em meados da década de oitenta, quando a miniaturização de sua prosa chama a atenção da crítica: "se os primeiros textos já eram diminutos, ocupando no máximo seis páginas, atualmente diminuíram ainda mais" (HOHLFELDT, 1988: 161).

Em resenha sobre Ah,é?, o também escritor Miguel Sanches Neto afirma que na obra "a rapidez, tida por Ítalo Calvino como uma das características deste milênio (...) é praticada por Trevisan de uma forma mais radical" (1996: 127). E depois de considerar sintomática que a edição tenha se dado no final deste milênio agonizante, afirma que a obra "representa para a ficção brasileira o que Pau-Brasil, de Oswald, representa para a nossa evolução poética" (1996: 128).

O livro, chamado pela edição de "ministórias", traz 187 narrativas sem título, apenas numeradas, histórias que retomam os temas eminentemente urbanos de uma humanidade perversa e pervertida, violenta e tarada, como assassinato, traição, pedofilia, (homo) sexualidade e abuso sexual. Não há, pelo menos nas primeiras edições, nenhum tipo de metatexto como prefácio ou apresentação, tampouco orelha ou contracapa - onde apenas são reproduzidas duas das ministórias -, o que ajuda a confundir e surpreender a crítica da época, mesmo acostumada à estética de Trevisan.

Marcelo Coelho, por exemplo, começou sua resenha na Folha de S. Paulo com a ilustrativa frase: "Dalton Trevisan é um escritor muito bom de ler e muito difícil de comentar" (1994: 5). Marco Chiaretti preferiu citar uma frase do próprio Trevisan - que não dá entrevistas, dele tem-se apenas fragmentos de conversas -, para justificar a designação de "haicai" para o conjunto:

É o próprio Trevisan quem melhor definiu seu novo livro, em uma espécie de auto-retrato composto há anos: "Há o preconceito de que depois do conto você deve escrever novela e afinal romance. Seu caminho será do conto para o soneto e para o haicai". Ele escreveu romance, A Polaquinha (de 1985). Ah, é? é o haicai. (1994: 5)

O próprio resenhista ressaltará, porém, que não há rima nos "minúsculos contos, mas a idéia de fulguração, de rápido clarão, contida no poema japonês, é o Leitmotiv da obra do escritor curitibano desde seu primeiro livro" (1994: 5). Adiante, Chiaretti falará da concisão da obra e da discrição da figura de Trevisan, a quem define como um dos maiores escritores brasileiros, e encerra com uma definição que talvez explique por que hoje chamam o curitibano de "grande mestre": "sua arte está na precisão. Trevisan mais que vampiro é cirurgião. Corta obsessivamente a "gordura" das palavras. Deixa o essencial. O verbo. O princípio" (1994: 7).

Vejamos como opera essa obsessão em uma das ministórias de Trevisan:

O velho em agonia, no último gemido para a filha:

- Lá no caixão...

- Sim, paizinho.

- ... não deixe essa aí me beijar. (TREVISAN, 1994: 122)

Esta narrativa, que é a $166^{\mathrm{a}}$ do livro, consegue com apenas 22 palavras apresentar duas personagens - e sugerir uma terceira - além de deixar latente a presença de um conflito, ainda que não saibamos com clareza qual. Na definição de Waldman (1994), seria um fragmento pinçado de uma das tantas narrativas de Trevisan em que há pai e filha, velho 
e morte, marido e mulher, transformando-se em mais um capítulo do que Dalton chamou de sua "ilíada doméstica". Mas lendo-a assim, isolada e única, percebe-se a completude da narrativa, uma completude garantida pela própria tradição criada pela obra de Trevisan, e é esta completude de um fragmento tão pequeno, a recriação do conto num espaço tão exíguo o que faz de $A h$, é? a grande obra para a minificção brasileira, sendo ou ela a pioneira deste miniconto à Monterroso no Brasil.

\section{O miniconto brasileiro contemporâneo}

A partir de $A h, e ́$ ?, operou-se uma espécie de reinvenção do gênero na nossa literatura, reinvenção e revitalização, pois diversos livros foram publicados a partir de então com minificções, suscitando novos debates e ampliando as possibilidades do gênero até chegarmos na antologia de 2004 citada como a primeira específica de miniconto, uma antologia que, como veremos, opera no limite desta estética.

Em 1996, Maria Lúcia Simões publica em Minas Gerais o livro Contos Contidos. Sem um limite expresso de número de caracteres, a autora parece levar em conta a totalidade de impressão, ou seja, o não virar a página, pois seus 61 contos cabem necessariamente em uma página. Nos textos a autora não abre mão do lirismo que exercitara em suas obras anteriores, de poesia, mas consegue produzir narratividade e despertar no leitor certo efeito contístico numa mescla que caracteriza sua produção e confunde os críticos. Ainda que o título do livro traga a palavra "contos", Otto Lara Resende, em trecho de crítica reproduzida na orelha da obra, diz que há de tudo nesses Contos Contidos, "poesia, filosofia, psicologia", assim como Affonso Romano de Sant'Anna, também na orelha da obra, diz que se trata de "uma revitalização do Hai-Kai em prosa moderna: síntese, lirismo e surpresa".

Na verdade, os mais de cinqüenta contos comprovam a possibilidade de narrar em exíguo espaço, como fizera Trevisan e como fariam outros tantos contistas ou poetas nos anos seguintes. Em 1998, por exemplo, são publicados O filantropo, de Rodrigo Naves, e Pérolas no decote, de Pólita Gonçalves, obras que chamam a atenção da professora Regina Dalcastagné.

Em artigo sobre a renovação e permanência do conto brasileiro, Dalcastagné pondera que em contos excessivamente breves fica difícil ir conduzindo o leitor, manipulando suas sensações para alcançar a emoção pretendida. Desta forma, considera malfadada a estréia do ficcionista Rodrigo Naves, cujos "flashes, de uma, duas páginas, às vezes até menos, reunidos em $O$ filantropo, de 1998, têm alguma poesia e humor, mas pouco ou nada dizem ao leitor" (2001: 10).

Caminho oposto teria seguido Pólita Gonçalves, que também estreara em 1998 com o livro Pérolas do Decote, onde "tece minicontos - cheios de poesia e de violência - que falam de traições e do medo do abandono. Na sua repetição, cada conto vai somando-se ao outro para formar um mosaico doloroso, que desenha a solidão" (2001: 11).

Também em 1998, mais precisamente em agosto, João Gilberto Noll começa a publicar pequenas narrativas na Folha de S. Paulo sob o título de "Relâmpagos". A publicação se estende até dezembro de 2001 e, dois anos depois, a reunião de 338 destes textos é publicada em Mínimos, múltiplos, comuns, que ganharia o Prêmio Academia Brasileira de Letras em 2004. Obra de difícil leitura e qualificação, não se atribui o gênero conto, e sim considera-se uma reunião de 338 "romances mínimos", relatos confinados a um máximo de 130 palavras.

Em 1999 é a vez do pernambucano Luiz Arraes iniciar a publicação de seus contos em miniatura. Ficcionista que então já contava quatro livros publicados, em $A$ luz e a 
fresta mescla pela primeira vez a contos mais longos outros com uma página ou até um parágrafo, como "Os amantes" e "O matador de aluguel". A obra marca o processo de miniaturização do conto por que passou Arraes, que em seus livros seguintes já optará por uma predominância dos mínis, até que em Anotações para um livro de baixo-ajuda ele investirá nos chamados microcontos e nos contos unifrásicos (a obra divide-se em duas partes, a primeira com 12 microcontos e a segunda com 14 variações de "O Dinossauro").

Dois mil e um, enfim, seria um ano muito importante para a minificção: Carlos Herculano Lopes lança Coração aos Pulos, alternando contos de várias páginas com minicontos de um parágrafo, Fernando Bonassi publica Passaporte, reunião de "micronarrativas de viagem", e Luiz Rufatto surpreende com Eles eram muitos cavalos, onde narra 70 histórias por ele chamadas de "flashes" da cidade de São Paulo. Três autores com alguma experiência e já reconhecidos na nova geração brasileira com três obras fundamentais para o estudo desta reinvenção do miniconto.

O mineiro Carlos Herculano Lopes é dos três o mais convencional, reunindo em Coração aos pulos 39 contos que tratam de temas como suicídio, morte, relações familiares distorcidas e conflito de identidade, permitindo-se alguns finais felizes e boa dose de surrealismo. Ainda que mescle contos longos e curtos (o conto que dá título ao livro tem seis páginas), predominam os mínis, de cem, centro e cinqüenta palavras, quando muito. Numa primeira leitura, os contos de Herculano Lopes lembram os contos da também mineira Maria Lúcia Simões, narrativas bem menores do que o conto convencional mas ainda não tão mínimas quanto as de nosso objeto. Em Coração aos pulos, porém, não há na edição uma discussão de gênero - como vimos na obra de Maria Lúcia. Os textos são chamados de contos e tanto a orelha quanto a contracapa da obra se dedicarão apenas a exaltar o autor, tido como um dos mais premiados da sua geração, e a obra.

Já as narrativas de Passaporte, do paulista Fernando Bonassi, não são chamadas pela edição de contos, e sim de "relatos de viagem". Escritas, sua maioria, entre maio e setembro de 1998 com bolsa do Kunstlerprogramm do DAAD (Deutscher Akademischer Austauschdienst), as narrativas não ultrapassam meia página e o autor acrescenta a cada texto um ano e uma cidade com seu respectivo país (em que supostamente o texto foi escrito), reforçando a idéia de um livro de viagens. Aqui já não surpreende mais a escassez de palavras (são menos de cem), tampouco os espaços vazios propositadamente deixados pelo texto, mas o livro chama a atenção pela reunião destes minicontos em um projeto de edição uno, no caso o de um "livro de viagens", demonstrando as diversas possibilidades do miniconto que o transformariam num verdadeiro gênero literário (mais tarde, em 2006, o gaúcho Leonardo Brasiliense publicaria Adeus contos de fadas, com minicontos juvenis, dando ao miniconto também um tratamento de gênero). Cabe ressaltar, ainda, que esta unidade temática dos textos permite que alguns vejam na obra uma espécie de romance fragmentado, situação que se intensifica na obra de Luiz Rufatto, Eles eram muitos cavalos.

Publicada pela editora Boitempo também em 2001, a obra traz 71 "flashes" da cidade de São Paulo no dia 9 de maio de 2000. Já na orelha do livro, que serve como apresentação, Fanny Abramovich confessa: "Não sei se li um romance ou novela, se contos, registros ou espantos... Sei que me joguei voraz pelos setenta flashes, takes, zoons avançados sobre a sufocante paulicéia". A obra ganhou o Prêmio da Associação Paulista de Críticos de Arte de melhor romance de 2001 e o Prêmio Machado de Assis, da Biblioteca Nacional, no mesmo ano. Além disso, tem sido objeto de diversos estudos acadêmicos, principalmente pela experimentação formal. 
Não por acaso também em 2001 uma obra didática publicada por Graça Paulino, Ivete Walty, Maria Nazareth Fonseca e Maria Zilda Cury, Tipos de textos, modos de leitura, considera, talvez pela primeira vez no Brasil, o miniconto como um gênero específico, colocando-o como item no capítulo "gênero de textos", ao lado da poesia, da crônica, do conto e do romance. Embora não avance nas definições e considerações sobre o miniconto, a obra apresenta de forma sintética uma definição para o que chama de gênero:

Embora o conto nos pareça uma narrativa concisa, restrita aos elementos essenciais,
desenvolveu-se, a partir dos anos 60 , um tipo de narrativa que tenta a economia
máxima de recursos para obter também o máximo de expressividade, o que resulta
num impacto instantâneo sobre o leitor. Trata-se do chamado miniconto. Seu efeito
de recepção é muito forte exatamente por sua condensação. O discurso direto, tão
freqüentente no conto, é muitas vezes dispensado em nome de um ritmo de narração
quase alucinante. Isso o transforma numa metáfora da velocidade com que circu-
lam os seres, as mensagens, os objetos, os textos nas sociedades contemporâneas.
(PAULINO, 2001: 137-8).

Afora toda essa produção, também no primeiro ano do novo milênio, de $\mathrm{Os} C e m$ Melhores Contos Brasileiros do Século, antologia organizada por Ítalo Moriconi com autores consagrados que vão de Machado de Assis a Moacyr Scliar, passando por Lima Barreto, Clarice Lispector, os Rubens Braga e Fonseca, os Andrades Mario e Carlos Drummond, Sérgio Sant'anna, Dalton Trevisan e outros tantos. A compilação inclui canônicos como "Pai Contra Mãe" e "Feliz Ano Novo", mas Moriconi já na apresentação alerta: "na seleção aqui apresentada foram feitas algumas escolhas pouco ortodoxas, que se justificam, além da qualidade intrínseca do texto, por indicar ao leitor a possibilidade do gênero conto" (2001: 15).

A partir dessa explicação o leitor não se surpreenderá ao encontrar contos com menos de duas páginas - ou minicontos - ao longo da antologia. Estão presentes "A mulher do vizinho", de Fernando Sabino, "Uma vela para Dario", de Dalton Trevisan, "Aí pelas três da tarde", de Raduan Nassar, "O peixe de ouro", de Haroldo Maranhão, "Gestalt", de Hilda Hilst e "Zap", de Moacyr Scliar, os dois primeiros identificados como dos anos sessenta, os três seguinte como dos anos setenta e o último como dos anos noventa. Como na antologia de Bosi, aqui os textos não trazem o rótulo de mínis, mas podemos ver essa inclusão como uma espécie de canonização dos minicontos, ou pelo menos como uma aceitação dessa possibilidade estética para o "conto em si”. O que talvez surpreenda, aí sim, é o último dos cem contos, uma reunião de quinze narrativas de Fernando Bonassi reunidas sob o título "15 cenas de descobrimento de Brasis". Trata-se de quinze micronarrativas independentes, com título, enredo e personagens independentes, sendo a unidade apenas a sugerida pelo título geral, ou seja, de que o cenário é o Brasil em processo de descobrimento. Algumas, como "Turismo ecológico", fazem referência ao descobrimento histórico - esta trata de um missionário e o conflito entre brancos e índios. Outras, como "Planalto Central", retratam um país do presente, mas ainda a ser descoberto.

É neste contexto do texto elíptico, fragmentado, já não tão ligado a poética do conto tradicional que surge, alguns anos depois de Os Cem Melhores, a antologia Os Cem Menores Contos Brasileiros do Século, organizada por Marcelino Freire em 2004 sob inspiração da antologia de Moriconi - ou como paródia desta. A proposta do organizador era publicar cem histórias inéditas com até cinqüenta letras, sem contar o título. A medida, aparentemente arbitrária, é o arredondamento do número de caracteres do microconto de Monterroso, "O Dinossauro", de 37 letras na versão em português - microconto que Freire chama de "o mais famoso do mundo". 
Entre os autores convidados por Freire estão alguns figurões como Millôr Fernandes, Moacyr Scliar, Manoel de Barros e, claro, Dalton Trevisan. O esqueleto do livro, porém, é formado pelos nomes da chamada "Geração 90", como Luiz Ruffato, André Sant' Anna, Fernando Bonassi, Marcelo Mirisola, Marçal Aquino, Ronaldo Bressane e Joca Reiners Terron.

O resultado é uma antologia desigual, com alguns textos muito próximos ao lirismo - lembrando o também reducionista haikai -, outros sem nenhuma significação aparente e ainda outros, talvez a maioria, jogando com maestria no limiar da narrativa. Vejamos um caso bem sucedido:

Uma vida inteira pela frente.

O tiro veio por trás. (MOSCOVICH, 2004: 16).

Estas dez palavras, estes quarenta caracteres (não conta-se os espaços nem a pontuação), são todo o conto. Não há título. Não há qualquer relação entre esta narrativa e a de qualquer outro autor. Ainda assim podemos identificar personagem, sucessão, conflito, história aparente e história oculta - como em "O dinossauro", evidenciando a possibilidade do miniconto unifrásico como gênero narrativo.

\section{Considerações finais}

Observando a produção contemporânea, parece evidente que o miniconto, ou minificção, tem conquistado seu espaço também no Brasil, seja pela grande massa de leitores e escritores de internet que o país tem, seja pela influência da literatura hispano-americana, seja pela pressa do leitor contemporâneo e a impaciência cada vez maior com a leitura.

Evidentemente o miniconto ainda tem um longo caminho de afirmação, mas deve convergir na busca pela narratividade como ponto fundamental. A partir daí, leitores, escritores e críticos saberão encontrar o ponto médio entre ocultação e revelação, mesmo que os textos tenham trinta ou cinqüenta letras, e se poderá, aí sim, reconhecer o nascimento de um novo gênero literário, com presença também no Brasil.

\section{Referências}

ANDRADE, Oswald. Manifesto da Poesia Pau-Brasil. In: TELES, Gilberto Mendonça (org.). Vanguarda européia e modernismo brasileiro. São Paulo, Vozes, 1972. p. 266-271. ANDRADE, Oswald. Memórias Sentimentais de João Miramar. São Paulo, Globo, 1991. ASSIS, Machado de. Memórias Póstumas de Brás Cubas. São Paulo, Objetivo, 1997. BONASSI, Fernando. Passaporte. Rio de Janeiro, Cosac Naify Edições, 2001. BOSI, Alfredo. História concisa da Literatura Brasileira. São Paulo, Cultrix, 1994. 42a ed. BOSI, Alfredo. O conto brasileiro contemporâneo. São Paulo, Cultrix, 1995. $11^{\mathrm{a}} \mathrm{ed}$. CAMPOS, Haroldo de. Arte pobre, tempo de pobreza, poesia menos. In: SCHWARZ, Roberto (org.). Os pobres na literatura brasileira. São Paulo, Editora Brasiliense, 1983. p. 181-189

CÂNDIDO, Antônio. A educação pela noite e outros ensaios. São Paulo, Ática, 1987. CÂNDIDO, Antônio; CASTELLO, J. Aderaldo. Presença da literatura brasileira: história e antologia. Rio de Janeiro, Bertrand Brasil, 1997.

CHIARETTI, Marco. Dalton Trevisan publica seu $23^{\circ}$ livro. Folha de S. Paulo - Ilustrada, São Paulo: 5-7, abril de 1994. 


\section{Conexão Letras}

COELHO, Marcelo. Trevisan apequena grandes obsessões. Folha de S. Paulo - Ilustrada, São Paulo: 5-14, julho de 1994.

DALCASTAGNÉ, Regina. Renovação e permanência: o conto brasileiro da última década. Estudos de Literatura Brasileira Contemporânea, Brasília, n. 11: 3-17, janeiro/ fevereiro de 2001.

DILL, Luís. Aventura. In: CHAFFE, Laís (org.). Contos de Bolso. Porto Alegre, Casa Verde, 2005. p. 96.

ERIK, Karl. Miniatura e fragmento: Brevíssima incursão pela formas breves do Brasil. In: NOGUEROL, Francisca (Org.). Escritos disconformes. Nuevos Modelos de Lectura. Salamanca, Universidad de Salamanca, 2004. p. 153-162

FACCIOLI, Cíntia Moscovich. O eloqüente silêncio: das oficinas de criação literária à conquista da competência para o conto. Porto Alegre: PUCRS, 2000. Dissertação (Mestrado em Letras), Faculdade de Letras, Pontifícia Universidade Católica do Rio Grande do Sul, 2000.

FREIRE, Marcelino (org.). Os Cem Menores Contos Brasileiros do Século. Cotia, Ateliê Editorial, 2004. 2 ed.

LAGMANOVICH, David. Microrrelato. Buenos Aires - Tucumán, Cuadernos de Norte y Sur, 2003.

LAGMANOVICH, David (org.). La otra mirada: antología del microrrelato hispánico. Valencia: Menoscuatro, 2005.

LOPES, Carlos Herculano. Coração aos pulos. Rio de Janeiro, Record, 2001

MORICONI, Ítalo (org.). Os Cem Melhores Contos Brasileiros do Século. Rio de Janeiro, Objetiva, 2001.

MOSCOVICH, Cíntia. (sem título). FREIRE, Marcelino (org.). Os Cem Menores Contos Brasileiros do Século. Cotia, Ateliê Editorial, 2004. 2 ed. p. 16

NOLL, João Gilberto. Mínimos, Múltiplos, Comuns. Rio de Janeiro, Francis, 2003

PAULINO, Graça [et al.]. Tipos de textos, modos de leitura. Belo Horizonte, Formato Editorial, 2001.

POE, Edgar Allan. Ficção Completa, poesia e ensaios. Trad. Oscar Mendes e Milton Amado. Rio de Janeiro: Nova Aguilar, 1997.

RUFATTO, Luiz. Eles eram muitos cavalos. São Paulo, Boitempo Editorial, 2001

SANCHES NETO, Miguel. Biblioteca Trevisan. Curitiba, Ed. da UFPR, 1996.

SIMÕES, Maria Lúcia. Contos contidos. Belo Horizonte, Editora RHJ, 1996

TREVISAN, Dalton. Ah, é?. Rio de Janeiro, Record, 1994. $2^{\text {a }}$ ed.

WALDMAN, Berta. O curto infinito de Trevisan. Folha de S. Paulo - Caderno Mais!, São Paulo: 6-10, abril de 1994. 